\title{
Consumption of indigenous medicines by pregnant women in North India for selecting sex of the foetus: what can it lead to?
}

Sutapa Bandyopadhyay Neogi ${ }^{1 *}$, Preeti H. Negandhi ${ }^{1}$, Abhijit Ganguli ${ }^{2}$, Sapna Chopra ${ }^{1}$, Navraj Sandhu ${ }^{3}$, Ravi Kant Gupta ${ }^{4}$, Sanjay Zodpey ${ }^{1}$, Amarjeet Singh ${ }^{5}$, Arun Singh ${ }^{6}$ and Rakesh Gupta ${ }^{4}$

\begin{abstract}
Background: Sex ratio is an important indicator of development. Despite all the measures undertaken for improvement, it remains an issue of concern in India, with Haryana having a very low sex ratio in the country. Studies have been conducted indicating that consumption of indigenous drugs used for sex selection (SSD) could be strongly associated with adverse effects on the foetal development, including congenital malformations. Some samples of SSDs were collected from parts of North India and analysed in a standard laboratory for its components.

Methods: Thirty SSDs used by the local community were procured from various sources in north India through a rigorous process of collection. These were subjected to laboratory tests to investigate the presence of phytoestrogen and testosterone. Following sample extraction, thin layer chromatography and high performance liquid chromatography were carried out for analysing phytoestrogen content.

Results: SSDs were available in various forms such as powder, tablets, mostly from faith healers. Around $87 \%$ of the samples collected from sources like doctors, quacks and faith healers were to be taken by the pregnant women after conception; $63 \%$ drugs were strongly positive for phytoestrogens (genistein, daidzein, formononetin) and $20 \%$ drugs were positive for testosterone. The average dose of the components as calculated after analyses was as follows: daidzein - $14.1 \mathrm{mg} / \mathrm{g}$ sample, genistein - $8.6 \mathrm{mg} / \mathrm{g}$ sample, formononetin - $5 \mathrm{mg} / \mathrm{g}$ sample.

Conclusion: These SSDs could be potentially detrimental to the growth and development of the foetus. This is likely to have implications on the health of the community. In view of the results obtained in our study, we strongly attest the importance in curbing this harmful practice by banning the supply of the drugs as well as by advocating behavioural changes in the community.
\end{abstract}

\section{Background}

Sex ratio has been an important indicator of development since decades. Census data for the past 100 years have shown a skewed pattern of the sex ratio in favour of males. Traditionally, it has been observed that there is a preference for sons in India. Various means to have a son include going through multiple pregnancies till a son is born, sex selective abortions, pre-conceptional techniques and post-conceptional intake of drugs to beget a male child. This has nation-wide implications, especially for issues such as female foeticide and health

\footnotetext{
* Correspondence: sutapa.bneogi@iiphd.org

'Indian Institute of Public Health-Delhi (IIPH-D), Public Health Foundation of India (PHFI), New Delhi, India

Full list of author information is available at the end of the article
}

care for the living girls. The PNDT Act (Pre Natal Diagnostic Technique) brought into force since 1994 banned the detection of sex of the foetus and has been a useful step towards curbing female foeticide. A subsequent amendment in 2002 brought pre-conceptional sex selection techniques also into its fold since people were resorting to pre-conceptional methods, thereby changing the PNDT Act to PCPNDT Act (Pre Conception, Pre Natal Diagnostic Technique). Despite all these measures, sex ratio continues to be a concern. Haryana, an Indian state, has one of the lowest sex ratios (879 females per 1000 males) in comparison to the national figure of 933 females per 1000 males [1, 2].

Besides sex selective abortions, several indigenous methods are in vogue for giving birth to a male child. 
Some of these include consumption of special diet before and after conception, timing and date of sexual intercourse (even dates such as 2nd, 4th, 6th of the month for male offspring or full moon/no moon) and reciting chants. The rituals adopted for conception of healthy male child is described as "Pumsavana karma." Intake of indigenous medicines for sex selection in India as well as the West is also documented [3, 4]. Anecdotal reports and research findings highlighting this practice have found their place in newspapers over the last two decades. In 1991, Government of Gujarat, India, banned the manufacture and sale of Select, a drug which was claimed to produce a male foetus if a pregnant woman consumed it for 45 days after her last menstrual period [5].

Consumption of indigenous medicines used for sex selection, also known as Sex Selection Drugs (SSD) during the first trimester of pregnancy is prevalent in certain parts of the country $[3,6,7]$. A case-control study was undertaken in the state of Haryana, India recently to investigate the risk factors for congenital malformations. Data regarding congenital malformations and the risk factors were collected from across all 21 districts of the state. Factors such as having more than two living children and the intake of sex selection drugs were found to be strongly associated with congenital malformations [8]. Similar reports were observed in an earlier hospital-based study [9]. It is important to note that SSDs are consumed during the most critical period of development of the embryo. To probe further into the details of the drugs consumed, some samples of SSDs were collected from various parts of North India and laboratory analyses were carried out to investigate the presence of certain components which might have an effect on the development of the embryo. The results of the analyses are presented here.

\section{Methods}

This study was undertaken as a part of a larger casecontrol study on "Risk factors of congenital malformations in Haryana" described elsewhere [8].

\section{Collection of SSDs}

In order to get information about the drugs, understand the methods of procuring them as well as collecting the drugs for analyses, the research team spoke to women who had delivered and also various genres of people including rickshaw pullers, drivers, cobblers and commoners in different areas of Haryana. Confidentiality was maintained throughout the study. It was indeed a tough task for the team to extract information about the suppliers of these drugs, since people maintained secrecy on this sensitive issue. It was observed that asking direct questions to the respondents would not help in extracting correct information, so information was gathered in a more informal and indirect manner. Finally, based on the information gained thus, the team managed to procure samples from various districts across the states of North India. Samples were collected and stored in polypropylene bottles in moisture-free conditions and transferred to the laboratory at Department of Biotechnology, Thapar University, Patiala for analyses within 17-24 h. They were stored in dark at $28{ }^{\circ} \mathrm{C}$.

\section{Biochemical analysis of SSDs}

A previous study had indicated that the SSDs contain steroids and testosterone [4]. The focus in the current research for laboratory investigations was restricted to testosterone and phytoestrogens in the drugs, since these are known to be the most commonly associated components to affect the development of the embryo. Owing to the high cost of the test kits for testosterone, this component was not tested in all of the procured samples. Phytoestrogen, however, was tested in all the procured samples. The following methods were used for analyses:

1. Sample extraction was done as proposed by Beck in 1964 [10]. All extracts were coded and analysed further.

2. Thin layer chromatography (TLC): The solvent system used was Chloroform/methanol (89: 11, v/v) on silica gel plates. All phytoestrogen standards (Sigma, Mo USA) could be visualized as blue-white fluorescent spots under UV light (257 nm). The experiment was repeated at least thrice to confirm initial authentication.

3. Identification and final quantitation High performance liquid chromatography (HPLC): All HPLC analyses were performed using a Reverse phase column (C-18) octadecylsilane (4 mm I.D $\times$ $30 \mathrm{~cm}$ ). Detector used was UV-VIS variable wavelength detector. Column temperature was maintained at $30{ }^{\circ} \mathrm{C}$. Detection of phytoestrogens was made at $254 \mathrm{~nm}$ (optical bandwidth $8 \mathrm{~nm}$ ).

Separation was achieved by using a linear methanolwater gradient system at a flow rate of $1.0 \mathrm{ml} / \mathrm{min}$. Methanol and water reservoirs each contained $1 \%$ glacial acetic acid $(\mathrm{v} / \mathrm{v})$ and $0.01 \mathrm{M}$ ammonium acetate HPLC grade by Casteele et al. [11].

The gradient was programmed to increase from 53 to $58 \%$ reservoir B (methanol) over $30 \mathrm{~min}$. Preliminary peak identification was based on a comparison of retention times of phytoestrogens standards and unknown peaks in the sample extracts.

The preliminary characterization of phytoesterogens by TLC in the drug samples was confirmed by HPLC analysis. A quantitation from HPLC peak area indicated the approximate quantities of each phytoestrogen. The 
results are presented as the proportion of samples detected positive for phytoestrogens and testosterone. Samples found strongly positive for these ingredients were subjected to further analyses and the average doses of each phytoestrogen consumed were calculated. Quantification of testosterone was however, not done.

\section{Ethical considerations}

The study was approved by Institutional Ethics Committee of Indian Institute of Public Health, Delhi. The participants of the study were mostly women who had delivered. Written consent was taken from them before interviewing after explaining to them about the study.

\section{Results}

A total of 30 samples were collected from various sources ranging from doctors/quacks to faith healers in North India.

The sources provided instructions for varied methods of consumption of the drugs. One such instruction included the consumption of this drug with cow's milk, to be consumed early morning without looking at any other female.

These drugs were given to the pregnant lady in specific doses to be consumed during the first trimester after confirmation of pregnancy, particularly during 6-10 weeks of pregnancy. They were available in different forms for consumption. Some drugs were to be taken in the form of a powder; some were in the form of tablets. In some cases, fruits injected with some medicines were also given. Some even gave a piece of paper with text written on it in a particular kind of ink to the pregnant lady for consumption. This paper was to be consumed with cow's milk. These drugs, famous for ensuring the birth of a male child upon consumption, are known locally as "sau badalne ki dawai". Some of these are available at a chemist's or a grocer's shop, with faith healers and local villagers. Rithaphal, Majuphal, Shivalingi are some of the common ingredients. These drugs are usually to be taken for 3-5 days or sometimes even for 21 days.

Out of the 30 samples collected, 26 (87\%) were supposed to be taken by women post-conception, three were to be consumed by males pre-conception and one by both the partners prior to conception. Nineteen samples (63\%) were strongly positive for all phytoestrogens (genistein, daidzein, formononetin). (Figures 1, 2) Testosterone was detected in three out of the 15 samples analysed for testosterone.

Quantitation of each phytoestrogen present was analysed from HPLC reports (Fig. 3, Table 1) An average dose was calculated thereafter based on this data and were as follows: daidzein: $14.10 \mathrm{mg} / \mathrm{g}$ sample, genistein: $8.52 \mathrm{mg} / \mathrm{g}$ sample, formononetin: $5.09 \mathrm{mg} / \mathrm{g}$ sample. The average weight of each sample was $10 \mathrm{~g}$ to be consumed

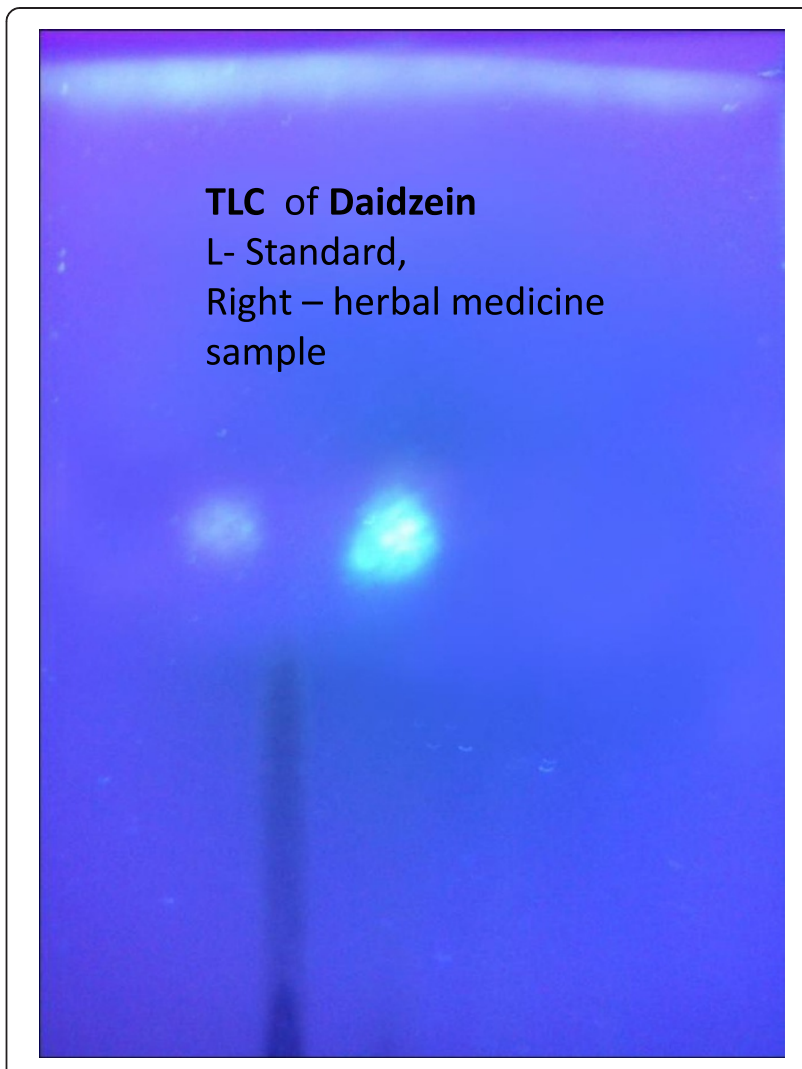

Fig. 1 Thin layer chromatography Spot of daidzein extracted from sex selection drugs

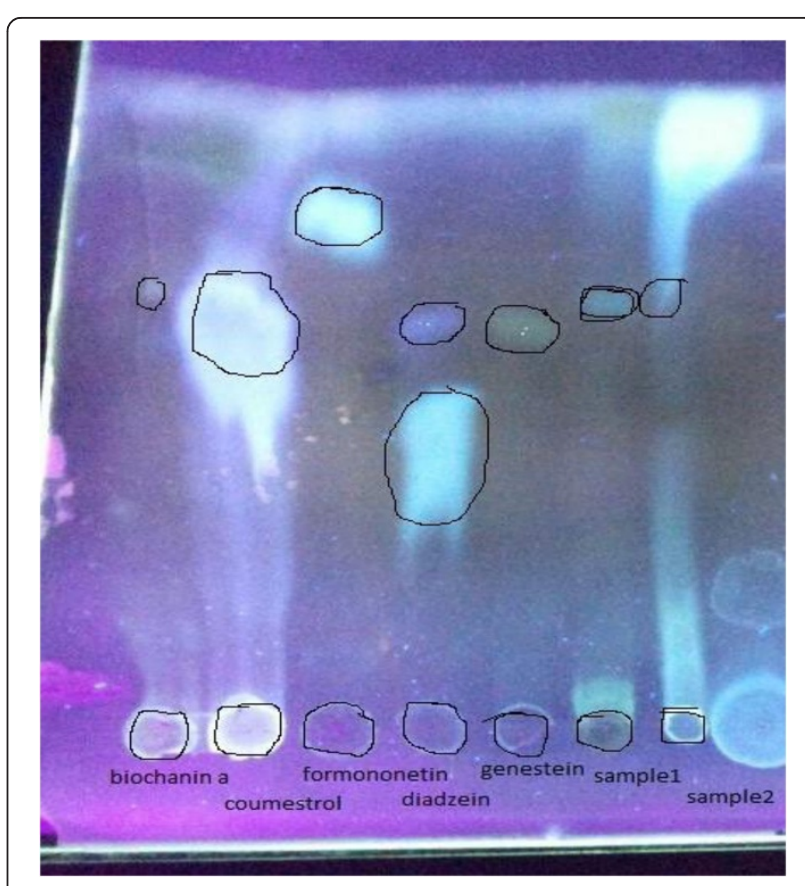

Fig. 2 Thin layer chromatography Spot of different phytoestrogens extracted from sex selection drugs 


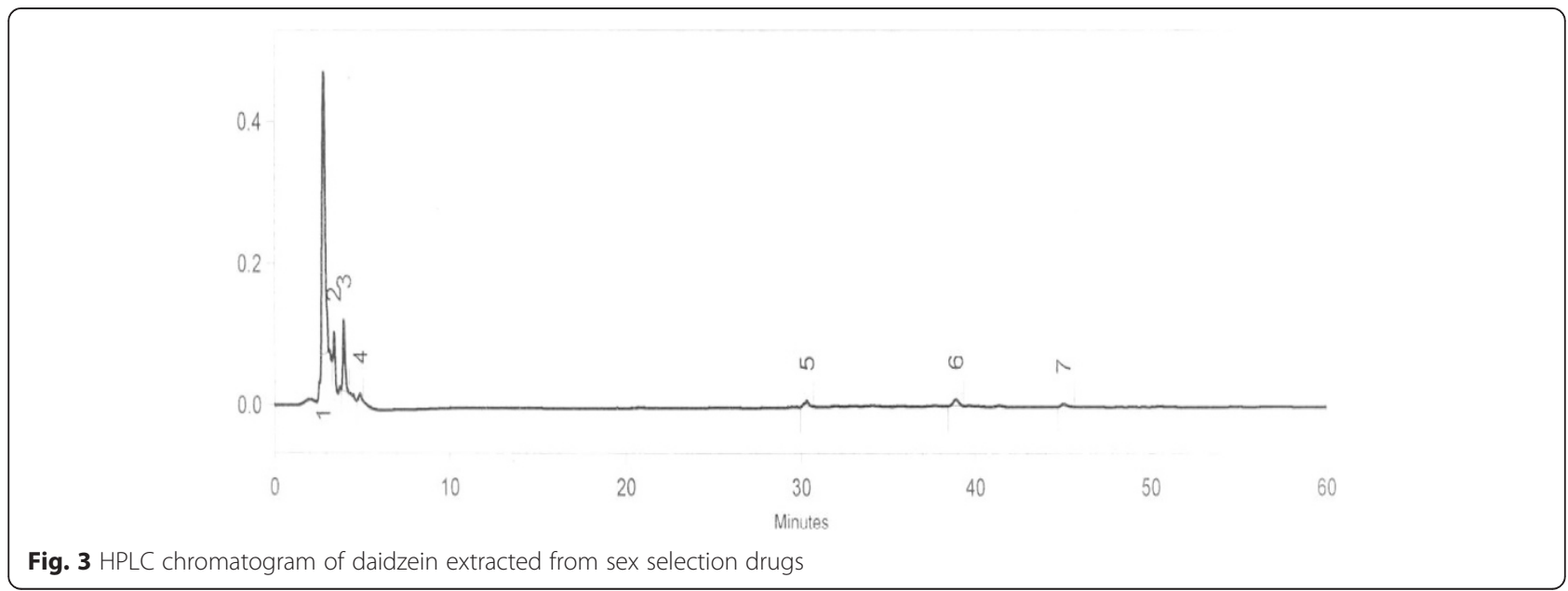

over a period of few days ranging from 3 to 21 days and hence daily dose was difficult to calculate. However, the total quantity to be consumed represents a ten-fold increase over that recommended for dietary intake $[12,13]$.

\section{Discussion}

Majority of the samples of SSDs collected in the study contained different phytoestrogens (daidzein, genistein and formononetin) in quantities that could be potentially detrimental to the growth and development of the embryo.

Phytoestrogens are plant derived edible items which show estrogen-like properties and are now recognized as endocrine disruptor compounds (EDCs). They can act as estrogenic agonists or antagonists capable of interfering with the synthesis, secretion and elimination of natural hormones in the body $[14,15]$. Studies indicate that human embryos and foetuses are exposed to phyestrogens and testosterone when mothers consume them during pregnancy [16-18]. Phytoestrogenic substances have shown to cross placental barrier and exposure of the embryo and foetus is directly related to maternal serum circulating levels of phytoestrogen [18-21]. Also, it is suggested that metabolic and/or excretion rates of phytoestrogens are different between mother and foetus and once phytoestrogens are transferred to the embryo and foetus, they tend to stay in foetal circulation longer than maternal circulation [21]. Animal studies indicate that testosterone too can cross the placental barrier [22-24].

It is extremely difficult to examine the effects of phytoestrogens or testosterone on human development and reproduction for ethical reasons. Evidence for concern emerges from laboratory based animal studies such as on rodents and to a lesser extent in primates. The observed effects can reliably predict what is likely to happen in humans [14].
Organogenesis occurs during 5-8 weeks of gestation in humans. Any insult during this period (including intake of phytoestrogens) can result in congenital malformations [25]. Sexual differentiation occurs between week 5 and 19 of pregnancy. Evidence on its probable effect can be extrapolated from studies in rodents. In them, sexual differentiation occurs from gestational days 12-20 [26]. Despite the differences in the periods when such alterations affect reproductive and brain structures and functions, the outcomes are largely consistent across species [27]. SSDs are consumed during 6-10 weeks of pregnancy which is a very critical period during the development of a foetus.

Although phytoestrogens mimic the effects of estradiol, their effects can produce estrogenic or anti-estrogenic effects depending on the phytoestrogen-estrogen ratio in the body. This partly explains why estrogenic effects predominate in livestock, whose estradiol plasma concentrations are relatively low. In contrast, anti-estrogenic effects are reported mainly in humans in which estrogen plasma levels are relatively high [28].

An adult woman can regulate the level of endogenous hormone production even when she is exposed to an exogenous phytoestrogen because of a mature hypothalamic pituitary gonadal (HPG) axis [29]. In embryonic life, when the reproductive system is developing, androgenic and estrogenic hormones can exert 'organizational' effects that permanently shape the reproductive system and its function. Thereafter, adjustments to the exposure of exogenous hormones cannot be made and it can lead to adverse effects of target organs. Secondly, inappropriate exposures can permanently alter the sensitivity to hormonal signals and alter the function of HPG axis across the lifespan. During puberty and adulthood, the same hormones exert 'activational' and 'functional' effects on a 'pre-formed' reproductive system [14, 26].

Early exposure of female embryo and foetus to phytoestrogens has also been associated with premature 
Table 1 Concentration of each phytoestrogen in samples of sex selection drugs

\begin{tabular}{|c|c|c|c|c|}
\hline Sample no & $\begin{array}{l}\text { Daidzein } \\
\text { (mg/g) }\end{array}$ & $\begin{array}{l}\text { Genistein } \\
(\mathrm{mg} / \mathrm{g})\end{array}$ & $\begin{array}{l}\text { Formonetin } \\
(\mathrm{mg} / \mathrm{g})\end{array}$ & Testosterone \\
\hline 1 & 1.00 & 8.80 & 6.00 & Not done \\
\hline 2 & 13.00 & 8.70 & 5.00 & Not done \\
\hline 3 & 13.00 & 8.50 & 5.00 & Not done \\
\hline 4 & 15.00 & 8.50 & 4.80 & +++ \\
\hline 5 & 15.00 & 8.60 & 4.80 & +++ \\
\hline 6 & 14.75 & 8.80 & 5.20 & +++ \\
\hline 7 & 14.30 & 9.20 & 5.40 & \pm \\
\hline 8 & 14.80 & 9.00 & 5.32 & \pm \\
\hline 9 & 14.78 & 8.80 & 5.00 & \pm \\
\hline 10 & 14.60 & 8.80 & 4.87 & \pm \\
\hline 11 & 15.40 & 8.40 & 4.88 & \pm \\
\hline 12 & 15.03 & 8.60 & 5.20 & \pm \\
\hline 13 & 16.20 & 9.00 & 5.40 & \pm \\
\hline 14 & 15.20 & 8.60 & 6.35 & \pm \\
\hline 15 & 15.30 & 8.70 & 6.00 & \pm \\
\hline 16 & 16.00 & 8.60 & 6.12 & \pm \\
\hline 17 & 15.00 & 8.50 & 5.00 & \pm \\
\hline 18 & 16.00 & 8.50 & 5.00 & \pm \\
\hline 19 & 15.00 & 9.00 & 4.89 & Not done \\
\hline 20 & 15.00 & 9.20 & 5.40 & Not done \\
\hline 21 & 14.88 & 9.10 & 5.00 & Not done \\
\hline 22 & 14.90 & 8.88 & 5.10 & Not done \\
\hline 23 & 14.60 & 8.70 & 4.93 & Not done \\
\hline 24 & 15.02 & 8.00 & 5.20 & Not done \\
\hline 25 & 15.40 & 8.04 & 5.10 & Not done \\
\hline 26 & 15.70 & 7.93 & 4.80 & Not done \\
\hline 27 & 15.50 & 8.40 & 4.20 & Not done \\
\hline 28 & 15.50 & 8.00 & 4.50 & Not done \\
\hline 29 & 9.67 & 7.30 & 4.30 & Not done \\
\hline 30 & 7.33 & 6.3 & 3.8 & Not done \\
\hline Median (mg/g) & 15 & 8.6 & 5 & \\
\hline Mean (mg/g) & 14.10 & 8.52 & 5.09 & \\
\hline SD & 3.01 & 0.58 & 0.53 & \\
\hline
\end{tabular}

thelarche, and breast cancer risks [30]. Acceleration of vaginal opening, altered oestrous cycles thereby advancing pubertal onset, a decline in fertility are some of the effects reported from exposure of animals to phytoestrogens during neonatal period $[14,31,32]$. On the other hand, exposure to testosterone can masculinize female offsprings [33-37]. What is important to note here is that even a single episode of exposure during this critical period can be harmful [27]. Early exposure of a male embryo and foetus to phytoestrogens disrupts the balance between androgen and estrogen and can impact the degree of masculinization of male foetus $[18,26]$. The more severe the interference, the more severe is the manifestation, with complete lack of masculinization (i.e. genotypic male with female genitalia) representing the most extreme consequence whereas hypospadias and cryptorchidism represent progressively milder consequences [38-41]. Animal experiments have shown that all testicular dysgenesis syndrome except testicular cancer can be induced by exposure of embryo to anti androgenic compounds [42].

Exposure of a male embryo and foetus to testosterone can negatively impact the reproductive development in terms of reduced sperm count and motility [34, 43, 44]. A study on guinea pigs also highlighted that excess of testosterone during pregnancy can produce hermaphrodites [45]. Prenatal testosterone also leads to infertility, obesity, intrauterine growth retardation and insulin resistance in adulthood [46-48]. With less interference, no obvious consequences may be evident at birth and may manifest only in adulthood.

Although sexual differentiation occurs in-utero among humans and rodents, sexual differentiation of the brain (which is dependent on androgens and estrogens) occurs in-utero in humans (between 12 and 24 weeks), but during the neonatal period in rodents (few days before birth till 10 days after birth) [49]. Early sexual differentiation of the developing brain is vulnerable to endocrine disruption by phytoestrogens which modify the organization of sexually differentiated neural pathways.

Testosterone and estradiol serve as the most important factors to establish permanent sex differences in brain organization [50]. The size of the sexually dimorphic nucleus of the pre-optic area (SDN) of the brain is larger in males than females and this is largely associated with sexual partner preference [18]. Exposure of male rats to resveratrol (estrogen) during neonatal period has been shown to be associated with smaller size of SDN and reduced socio-sexual behaviour in adulthood. Exposure to testosterone is also known to suppress female behaviour of the foetus in rats [27, 33, 36, 51].

Effects of endocrine disruption in the developing foetus are likely to be subtle and not readily apparent at birth, a lesson learnt from the disastrous case of DES (diethylstilbestrol). DES, a synthetic estrogen prescribed to prevent miscarriage ultimately turned out to be a cause of vaginal dysplasia, cervical adenosis and malformations of uterus and cervix. It is therefore important to consider the 'critical windows of exposure' when attempting to predict potential consequences of human exposure to endocrine disruptors like phytoestrogens [52-54].

The findings of the laboratory tests warrant further detailed analyses of larger numbers of samples and animal studies to explore the possible toxic effects of these 
components. Only a small number of samples were available for the analyses; a larger number with representation of more areas across North India, from different sources would have benefitted the results and their implications on the harmful practice of consumption of SSDs. Also, the analyses were done to test for presence of phytoestrogens and testosterone only, owing to their known effect on the development of the embryo. However, there might be other components in the drugs that might have had an effect on the embryonic development and growth; these could not be analysed due to logistic and financial constraints. Despite the limitations of the study, the results of the analyses proving the presence of fairly large proportions of phytoestrogens and testosterone in the drugs substantiate the need to curb this harmful practice for the benefit of the society at large. The results obtained from the analyses are reliable since the analyses were conducted by an experienced professional, using standardized methods at a reputed laboratory in North India.

Intake of SSD is a harmful practice quite prevalent in North India. It has been observed largely that these drugs are prescribed by faith healers and illegal practitioners largely, who knowingly or unknowingly, engage in not only an unethical, but a very risky procedure for the patients and the growing embryo. It is imperative that this dangerous practice be relinquished at the earliest. The availability of such drugs in local chemist shops, and with faith healers can be monitored through rigorous checks with the involvement of sectors other than health.

Banning the supply of these drugs will only solve part of the problem. In Indian communities, there are certain deep-rooted cultural and social customs which have evolved over the years. Hindu scriptures mention that if a son sets fire to the funeral pyre for his parents, they would be released from the travails of this world and their soul would enter heaven. The dowry system of giving gifts to the daughter and her in-law's family at the time of her marriage, still prevalent in many parts of the country, is another social tradition [3]. These traditions and rituals are considered as normal practice and behaviour, making them that much more difficult to curb. Traditions like these increase the demand for a male child among these communities. It is therefore prudent to bring about a positive change in the attitudes and behaviours of the community towards the female child. Various innovative schemes have been launched at the Central and State levels to highlight this important social issue and provide more support to a girl child. More needs to be done for long term gains at the community level. Making the implementation of PCPNDT Act more stringent at all levels, with punitive action taken against those who violate this law within the public as well as private health systems can be one of the steps in this direction. Behaviour change communication programs should be planned and implemented at the community level, targeting families, to change their mind-set regarding these traditions and practices. Although this will take time to be widely accepted, in the long run these interventions will help in stopping female foeticide, and in improving the status of female children in Indian communities.

\section{Conclusion}

Son preference is a phenomenon that we are grappling with in India. SSDs are consumed during the first trimester of pregnancy to have a male baby. Consumption of such drugs is dangerous and detrimental to the growth and development of the embryo since these contain phytoestrogens and testosterone in amounts beyond the acceptable quantities. This is likely to have long term implications on the health of the community. It is important to inform the community of the harms that these practices can cause in the long run.

\section{Abbreviations}

DES: Diethylstilbestrol; EDC: Endocrine disruptor compounds; HPG: Hypothalamic pituitary gonadal; HPLC: High performance liquid chromatography; PCPNDT: Pre conception, pre natal diagnostic technique; PNDT: Pre natal diagnostic technique; SDN: Sexually dimorphic nucleus; SSD: Sex selection drugs; TLC: Thin layer chromatography.

\section{Competing interests}

The authors declare that they have no competing interests.

\section{Authors' contributions}

SN conceptualized the study, designed it and drafted the manuscript. She provided overall leadership to the work. PN coordinated the project, and drafted the manuscript. AG performed the analysis of the drugs, compiled and interpreted the results. He also contributed significantly to finalizing the manuscript. SC helped in data collection, did the literature review and developed the manuscript. SZ helped in the analysis and interpretation of study findings and approved the final draft of the manuscript. AS (both) contributed towards designing the study and improving the manuscript. RKG, NS and RG coordinated with the research team to facilitate data collection, gave critical inputs and approved the final draft of the manuscript. All the authors have read and approved the final version of the manuscript

\section{Acknowledgements}

The research team acknowledges the contribution of Dr Amit Phogat Dr Rupinder Sahota and Dr Deepika Gupta from National Health Mission (NHM), Haryana for their support extended for the completion of the study. The team also appreciates the work of Mr Shamlal Sikri for his contribution in data collection. The team recognizes the contribution of Ajay Kumar and Pallak Jain of Department of Biotechnology, Thapar University for carrying out the analysis. Due credit is being given to National Institute of Pharmaceutica Education and Research (NIPER) for conducting the HPLC analysis. The authors deeply acknowledge the financial support provided by NHM Haryana for the execution of the study.

\section{Author details}

${ }^{1}$ Indian Institute of Public Health-Delhi (IIPH-D), Public Health Foundation of India (PHFI), New Delhi, India. ${ }^{2}$ Thapar University, Patiala, India. ${ }^{3}$ Government of Haryana, Chandigarh, India. ${ }^{4}$ National Health Mission, Panchkula, Haryana, India. ${ }^{5}$ Department of Community Medicine, Post Graduate Institute of Medical Education and Research, Chandigarh, India. ${ }^{6}$ Rashtriya Bal Suraksha Karyakram, Government of India, New Delhi, India.

Received: 23 November 2014 Accepted: 2 September 2015

Published online: 04 September 2015 


\section{References}

1. CensusInfo India. Haryana Profile. Office of the Registrar General and Census Commissioner, India. 2011 [16 October 2014]. Available from: www.censusindia.gov.in/2011-common/census_info_2011.html.

2. Ministry of Home Affairs Gol. Census of India Office of the Registrar General and Census Commissioner 2011 [16 October 2014]. Available from: censusindia.gov.in

3. Bandyopadhyay S, Singh AJ. History of son preference and sex selection in India and in the west. Bull Ind Inst Hist Med. 2003;XXXIII:149-67.

4. Bandyopadhyay S, Singh AJ. Sex Selection through traditional drugs in rural north India. Ind J Commun Med. 2007;32:32-4.

5. Unnikrishnan PV. Banned - Select: "a drug to alter the sex of the foetus". Health Millions. 1993;1(2):29-30.

6. Bhagat N, Laskar AR, Sharma. N. Women's perception about sex selection in an urban slum in Delhi. J Reprod Infant Psychol. 2012;30(1):92.

7. Manchanda S, Saikia B, Gupta N, Chowdhary S, Puliyel JM. Sex ratio at birth in India, its relation to birth order, sex of previous children and use of indigenous medicine. PLoS One. 2011;6(6):e20097.

8. Neogi SB, Negandhi PH, Sandhu N, Gupta RK, Ganguli A, Zodpey S, et al. Indigenous medicines use for sex selection during pregnancy and risk of congenital malformations: a population based case-control study in Haryana, India. Drug Safety. 2015. doi:10.1007/s40264-015-0309-5.

9. Panda C, Singh A. Risk factors of Congenital Malformations reporting at PGIMER, Chandigarh- a case control study: Post Graduate Institute of Medical Education and Research Chandigarh; MPH thesis. 2007.

10. Beck AB. The oestrogenic isoflavones of Subterranean clover. Aust J Agric Res. 1964;15:223.

11. Casteele KV, Geiger H, Sumere CFV. Separation of flavonoids by reversephase high-performance liquid chromatography. J Chromatogr. 1982;240:81.

12. Scientific Opinion of the Panel on Dietetic Products Nutrition and Allergies. EFSA J. 2009;997:1-19.

13. Al-Anazi AF, Qureshi VF, Javaid K, Qureshi S. Preventive effects of phytoestrogens against postmenopausal osteoporosis as compared to the available therapeutic choices: an overview. J Nat Sci Biol Med. 2011;2(2):154-63. doi:10.4103/0976-9668.92322.

14. Patisaul HB, Jefferson W. The pros and cons of phytoestrogens. Front Neuroendocrinol. 2010;31(4):400-19.

15. Retana-Marquez S, Hernandez H, Flores JA, Munoz-Gutierrez M, Duarte G, Vietma J, et al. Effects of phytoestrogens on mammalian reproductive physiology. Trop Subtrop Agroecosystems. 2012;15(Sup 1):S129-S45.

16. Foster WG, Chan S, Platt L, Hughes Jr CL. Detection of phytoestrogens in samples of second trimester human amniotic fluid. Toxicol Lett. 2002;129(3):199-205.

17. Franke AA, Custer LJ, Wang W, Shi CY. HPLC analysis of isoflavonoids and other phenolic agents from foods and from human fluids. Proc Soc Exp Biol Med. 1998;217(3):263-73.

18. Jefferson WN, Patisaul HB, Williams CJ. Reproductive consequences of developmental phytoestrogen exposure. Reproduction. 2012;143(3):247-60.

19. Balakrishnan B, Thorstensen EB, Ponnampalam AP, Mitchell MD. Transplacental transfer and biotransformation of genistein in human placenta. Placenta. 2010;31(6):506-11.

20. Degen $\mathrm{GH}$, Janning P, Diel P, Michna H, Bolt HM. Transplacental transfer of the phytoestrogen daidzein in DA/Han rats. Arch Toxicol. 2002;76(1):23-9.

21. Todaka E, Sakurai K, Fukata H, Miyagawa H, Uzuki M, Omori M, et al. Fetal exposure to phytoestrogens-the difference in phytoestrogen status between mother and fetus. Environ Res. 2005:99(2):195-203.

22. Gitau R, Adams D, Fisk NM, Glover V. Fetal plasma testosterone correlates positively with cortisol. Arch Dis Child Fetal Neonatal Ed. 2005;90(2):F166-9.

23. Sathishkumar K, Elkins R, Chinnathambi V, Gao H, Hankins GD, Yallampalli C. Prenatal testosterone-induced fetal growth restriction is associated with down-regulation of rat placental amino acid transport. Reprod Biol Endocrinol. 2011;9:110.

24. Vreeburg JT, Woutersen PJ, Ooms MP, van der Werff ten Bosch JJ. Androgens in the fetal guinea-pig after maternal infusion of radioactive testosterone. J Endocrinol. 1981;88(1):9-16.

25. Knight DC, Eden JA. Phytoestrogens â€" a short review. Maturitas. 1995;22(3):167-75.

26. COT Working Group. Effect of phytoestrogen on fertility and development. COT working group. [13 April 2015] Available from: http://www.food.gov.uk/ science/ouradvisors/toxicity/COTwg/wg_phyto/.
27. Hines M. Prenatal testosterone and gender-related behaviour. Eur J Endocrinol. 2006;155 Suppl 1:S115-21.

28. Adlercreutz H, Mazur W. Phyto-oestrogens and Western diseases. Ann Med. 1997:29(2):95-120.

29. Effects of phytoestrogens on fertility and development [26 September 2014]. Available from: http://multimedia.food.gov.uk/multimedia/worddocs/ phytoreport09.doc.

30. Zung A, Glaser T, Kerem Z, Zadik Z. Breast development in the first 2 years of life: an association with soy-based infant formulas. J Pediatr Gastroenterol Nutrit. 2008;46(2):191-5.

31. Obst JM, Seamark RF. Plasma progesterone concentrations during the reproductive cycle of ewes grazing Yarloop clover. J Reprod Fertil. 1970;21(3):545-7.

32. Liu H, Zhang C, Zeng W. Estrogenic and antioxidant effects of a phytoestrogen daidzein on ovarian germ cells in embryonic chickens. Domest Anim Endocrinol. 2006;31(3):258-68.

33. Rhees RW, Kirk BA, Sephton S, Lephart ED. Effects of prenatal testosterone on sexual behavior, reproductive morphology and LH secretion in the female rat. Dev Neurosci. 1997;19(5):430-7.

34. Wolf CJ, Hotchkiss A, Ostby JS, LeBlanc GA, Gray LE. Effects of prenatal testosterone propionate on the sexual development of male and female rats: a dose-response study. Toxicol Sci. 2002;65(1):71-86.

35. Gerall AA, Ward IL. Effects of prenatal exogenous androgen on the sexual behavior of the female albino rat. J Comp Physiol Psychol. 1966;62(3):370-5.

36. Huffman L, Hendricks SE. Prenatally injected testosterone propionate and sexual behavior of female rats. Physiol Behav. 1981;26(5):773-8.

37. McCoy SJ, Shirley BA. Effects of prenatal administration of testosterone and cortisone on the reproductive system of the female rat. Life Sci. 1992;50(9):621-8.

38. Clark BJ, Cochrum RK. The steroidogenic acute regulatory protein as a target of endocrine disruption in male reproduction. Drug Metab Rev. 2007:39(2-3):353-70

39. North K, Golding J. A maternal vegetarian diet in pregnancy is associated with hypospadias. The ALSPAC Study Team. Avon Longitudinal Study of Pregnancy and Childhood. BJU Int. 2000;85(1):107-13.

40. Williams K, McKinnell C, Saunders PT, Walker M, Fisher JS, Turner KJ, et al. Neonatal exposure to potent and environmental oestrogens and abnormalities of the male reproductive system in the rat: evidence for importance of the androgen-oestrogen balance and assessment of the relevance to man. Hum Reprod Update. 2001;7(3):236-47.

41. Lehraiki A, Chamaillard C, Krust A, Habert R, Levacher C. Genistein impairs early testosterone production in fetal mouse testis via estrogen receptor alpha. Toxicol In Vitro. 2011;25(8):1542-7.

42. Wohlfahrt-Veje C, Main KM, Skakkebaek NE. Testicular dysgenesis syndrome: foetal origin of adult reproductive problems. Clin Endocrinol (Oxf). 2009;71(4):459-65.

43. Clarke IJ, Scaramuzzi RJ, Short RV. Ovulation in prenatally androgenized ewes. J Endocrinol. 1977;73(2):385-9.

44. Recabarren SE, Rojas-Garcia PP, Recabarren MP, Alfaro VH, Smith R, Padmanabhan $V$, et al. Prenatal testosterone excess reduces sperm count and motility. Endocrinology. 2008;149(12):6444-8.

45. Phoenix CH, Goy RW, Gerall AA, Young WC. Organizing action of prenatally administered testosterone propionate on the tissues mediating mating behavior in the female guinea pig. Endocrinology. 1959;65:369-82.

46. Manikkam M, Crespi EJ, Doop DD, Herkimer C, Lee JS, Yu S, et al. Fetal programming: prenatal testosterone excess leads to fetal growth retardation and postnatal catch-up growth in sheep. Endocrinology. 2004;145(2):790-8

47. Abbott DH, Dumesic DA, Eisner JR, Colman RJ, Kemnitz JW. Insights into the development of polycystic ovary syndrome (PCOS) from studies of prenatally androgenized female rhesus monkeys. Trends Endocrinol Metab. 1998;9(2):62-7.

48. Steckler T, Wang J, Bartol FF, Roy SK, Padmanabhan V. Fetal programming prenatal testosterone treatment causes intrauterine growth retardation, reduces ovarian reserve and increases ovarian follicular recruitment. Endocrinology. 2005;146:3185-93.

49. Becu-Villalobos D, Gonzalez Iglesias A, Diaz-Torga G, Hockl P, Libertun C. Brain sexual differentiation and gonadotropins secretion in the rat. Cell Mol Neurobiol. 1997;17(6):699-715. 
50. Arnold AP. The organizational-activational hypothesis as the foundation for a unified theory of sexual differentiation of all mammalian tissues. Horm Behav. 2009:55(5):570-8.

51. Gandelman R, Simon NG, McDermott NJ. Prenatal exposure to testosterone and its precursors influences morphology and later behavioral responsiveness to testosterone of female mice. Physiol Behav. 1979;23(1):23-6.

52. Rubin MM. Antenatal exposure to DES: lessons learned...future concerns. Obstet Gynecol Surv. 2007;62(8):548-55.

53. Palmlund $\mathrm{I}$. Exposure to a xenoestrogen before birth: the diethylstilbestrol experience. J Psychosom Obstet Gynaecol. 1996;17(2):71-84

54. Newbold RR, Padilla-Banks E, Jefferson WN. Adverse effects of the model environmental estrogen diethylstilbestrol are transmitted to subsequent generations. Endocrinology. 2006;147 Suppl 6:S11-7.

\section{Submit your next manuscript to BioMed Central and take full advantage of:}

- Convenient online submission

- Thorough peer review

- No space constraints or color figure charges

- Immediate publication on acceptance

- Inclusion in PubMed, CAS, Scopus and Google Scholar

- Research which is freely available for redistribution 